\title{
Integration of Fiber-Reinforced Polymers in a Life Cycle Assessment of Injection Molding Process Chains with Additive Manufacturing
}

Hofstätter, Thomas; Bey, Niki; Mischkot, Michael; Stotz, Philippe Maurice; Pedersen, David Bue; Tosello, Guido; Hansen, Hans Nørgaard

\section{Published in:}

Industrializing Additive Manufacturing - Proceedings of Additive Manufacturing in Products and Applications AMPA2017

Link to article, DOI:

10.1007/978-3-319-66866-6_27

Publication date:

2017

Document Version

Peer reviewed version

Link back to DTU Orbit

Citation (APA):

Hofstätter, T., Bey, N., Mischkot, M., Stotz, P. M., Pedersen, D. B., Tosello, G., \& Hansen, H. N. (2017). Integration of Fiber-Reinforced Polymers in a Life Cycle Assessment of Injection Molding Process Chains with Additive Manufacturing. In M. Meboldt, \& C. Klahn (Eds.), Industrializing Additive Manufacturing - Proceedings of Additive Manufacturing in Products and Applications - AMPA2017 (pp. 287-295). Springer.

https://doi.org/10.1007/978-3-319-66866-6_27

\section{General rights}

Copyright and moral rights for the publications made accessible in the public portal are retained by the authors and/or other copyright owners and it is a condition of accessing publications that users recognise and abide by the legal requirements associated with these rights.

- Users may download and print one copy of any publication from the public portal for the purpose of private study or research.

- You may not further distribute the material or use it for any profit-making activity or commercial gain

- You may freely distribute the URL identifying the publication in the public portal 


\title{
Integration of Fiber-Reinforced Polymers in a Life Cycle Assessment of Injection Molding Process Chains with Additive Manufacturing
}

\author{
Thomas Hofstätter ${ }^{1}$, Niki Bey², Michael Mischkot ${ }^{1}$, Philippe M Stotz ${ }^{2}$, David \\ B Pedersen ${ }^{1}$, Guido Tosello ${ }^{1}$, and Hans N Hansen ${ }^{1}$ \\ 1 DTU Mechanical Engineering, Technical University of Denmark \\ 2800 Kongens Lyngby, Denmark, \\ thohof s@mek.dtu.dk \\ 2 DTU Management Engineering, Technical University of Denmark \\ 2800 Kongens Lyngby, Denmark
}

\begin{abstract}
Additive manufacturing technologies applied to injection molding process chain have acquired an increasingly important role in the context of tool inserts production, especially by vat polymerization. Despite the decreased lifetime during their use in the injection molding process, the inserts come with improvements in terms of production time, costs, flexibility, as well as potentially improved environmental performance as compared to conventional materials in a life cycle perspective.

This contribution supports the development of additively manufactured injection molding inserts with the use of fiber-reinforced vat polymerization technology. The life cycle assessment of the prototyping process chain for rapid prototyping with high flexibility provides a base for industrial applications in injection molding.
\end{abstract}

Keywords: Fiber-reinforced Polymers, Life Cycle Assessment, Additive Manufacturing, Injection Molding, Process Chains

\section{Introduction}

The conventional injection molding (IM) pilot production cycle is modified in a form where the cavity of the steel mold is generalized in geometry making room for inserts shaping the final geometry of the produced part. The generalized cavity is equipped with a smaller insert which is cheaper and more flexible in production and handling. Those standard inserts can be manufactured conventionally by milling of metals.

Newly developed technologies such as additive manufacturing (AM) show their major advantages in terms of flexibility and speed of production.[1-5] Moreover, finer details such as corners are limited to the voxel size of the AM machine (in the lower $\mu \mathrm{m}$ range), not the diameter of the milling machine.

Prior investigations by $[6,7]$ have shown a significant difference in potential environmental contributions such as Climate Change (Global Warming Potential, GWP) [8] and Human Toxicity (HT) [9] of IM inserts made from photopoly- 
mer exposed in a vat polymerization (VP) process $[10,1]$ compared to conventional inserts made from brass and steel. Despite the described advantages, the lifetime (i.e. number of shots) of AM inserts is significantly lower than the lifetime of conventionally machined metal tools. A general review on environmental impact of AM compared to conventional manufacturing was performed by [11].

This investigation targets the life cycle of an advancement of IM inserts by fiber-reinforced polymers (FRPs) [12,13]. Introduced by [1], FRPs in IM inserts reduced the crack propagation velocity in the insert and increased the lifetime by a factor of 2.6 at $5 \%_{\mathrm{wt}}$ short carbon fibers (CFs) and 5.2 at $10 \%_{\mathrm{wt}}$ compared to plain inserts without fiber-reinforcement as well as inserts made conventionally from aluminum, brass and steel. $[1,14,15]$

This paper elaborates on previous research by comparing plain inserts without fibers to FRP inserts in the perspective of a life cycle assessment (LCA) according to ISO 14040/44 [16] on screening level. It therefore contributes to the understanding of the effects if IM with AM inserts on environmental factors.

\section{Methods}

The LCA was performed on inserts produced with the proprietary photopolymer HTM-140 by the company Envisiontec. The inserts were shaped in the dimensions of $3 \mathrm{~mm} \times 19 \mathrm{~mm} \times 19 \mathrm{~mm}$ equipped with micro features such as sharp corners, cylindrical cavities and edges as shown in Fig. 1.

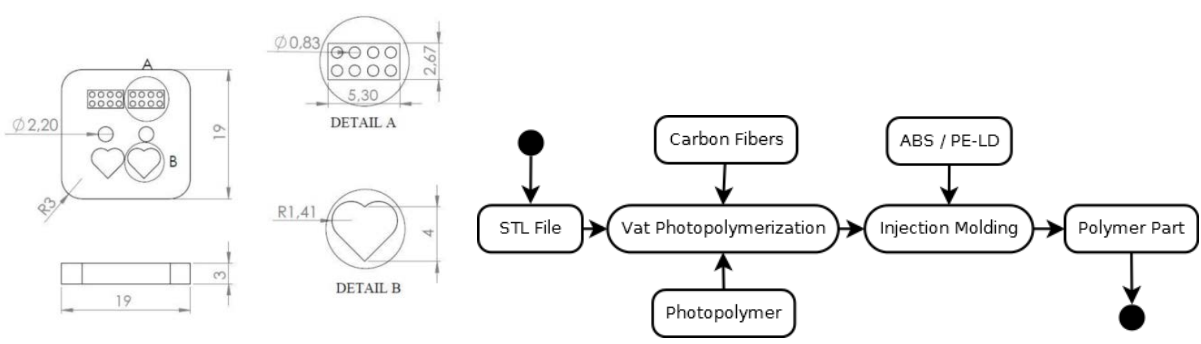

Fig. 1. Geometry of the investigated insert with sharp corners, cylindrical cavities and edges (left, source: [10], used with permission) and diagram of the IM process (right).

The FRP inserts were produced from a mixture of $5 \% \mathrm{wt}$ and $10 \% \mathrm{wt}$ of short virgin carbon fibers with dimensions $7.2 \mu \mathrm{m}$ diameter and $100 \mu \mathrm{m}$ average length [17]. They were modeled in SimaPro according to $[18,19]$ and will be referred to as VP $0 \%$, VP $5 \%$, and VP $10 \%$.

The manufactured inserts were grouped to a number of 4 inserts since the tool used 4 inserts per shot as shown in Fig. 2 whereas each insert of the compared materials had different specific weights shown in Table 1 . The material is injected from the back of the machine from a granular primary material. The IM process parameters were not changed from conventional IM manufacturing. Therefore, 
the process was also not included in the LCA as the focus is on the comparison of different insert materials as well as the impact of waste generation on the IM process.

The lifetime was experimentall determined for PE-LD as part material in [7, $1,14,15]$ and is listed in Table 2 . It can be expected that the lifetime of ABS as part material is lower due to the higher process temperature.
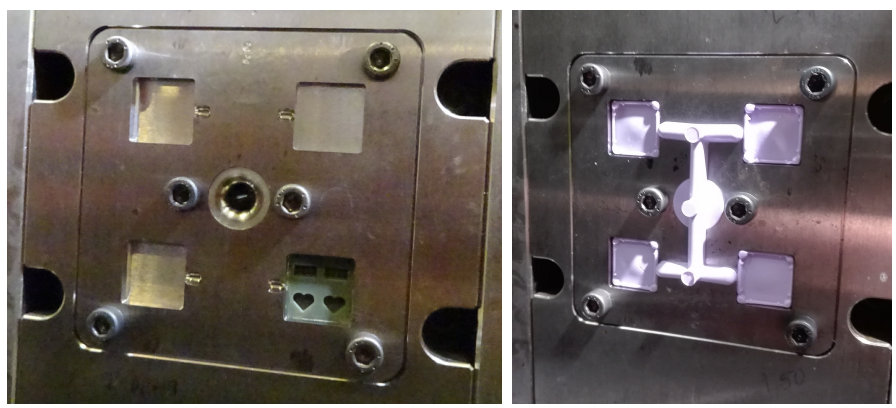

Fig. 2. Single insert in the IM machine (left). The process has a capacity of 4 inserts producing one part each. All inserts are connected by hot runners (right) resulting in waste material (source: [1], used with permission).

\begin{tabular}{c|c|c|c|c|c} 
VP $0 \%$ & VP $5 \%$ & VP $10 \%$ & aluminum & brass & steel \\
\hline $1.3 \mathrm{~g}$ & $1.325 \mathrm{~g}$ & $1.35 \mathrm{~g}$ & $3.2 \mathrm{~g}$ & $10.2 \mathrm{~g}$ & $9.4 \mathrm{~g}$ \\
Table 1. Weight of 1 insert of the different kinds.
\end{tabular}

Table 1. Weight of 1 insert of the different kinds.

\begin{tabular}{c|c|c|c|c|c} 
VP 0 \% & VP 5\% & VP $10 \%$ & aluminum & brass & steel \\
\hline 500 shot & 1300 shot & 2600 shot & 10000 shot & 10000 shot & 10000 shot
\end{tabular}

Table 2. Lifetime of 1 insert of the different kinds for injection of PE-LD as determined from $[7,1,14,15]$.

In order to investigate the inserts' share of environmental impact of the entire IM process, the waste of injected polymer was additionally calculated and compared to the used inserts. Acrylonitrile butadiene styrene (ABS) and Lowdensity polyethylene (PE-LD) were chosen as injected materials. The weight characteristic of 1 shot is shown in Table 3. Polymer waste is responsible for approximately $60 \%$ of the injected polymer weight in the process. 


\begin{tabular}{l|c|c} 
& ABS & PE-LD \\
\hline weight of 4 parts & $2.00 \mathrm{~g}$ & $1.60 \mathrm{~g}$ \\
weight of waste & $2.72 \mathrm{~g}$ & $2.28 \mathrm{~g}$ \\
total weight & $4.72 \mathrm{~g}$ & $3.88 \mathrm{~g}$
\end{tabular}

Table 3. Weight of 4 produced parts and residual material of the IM process that was not used in the final parts for 1 shot.

It was chosen to use GWP in $\mathrm{CO}_{2}$ equivalent as well as $\mathrm{HT}$ in $\mathrm{kg} 1,4-\mathrm{DB}$ equivalent, as indicators for the life cycle impact of the investigated inserts and parts.

\section{Results}

It was shown that the GWP increased at increasing CF content whereas the contributions to HT decreased. An increase in GWP of approximately $5 \%$ and a reduction of $\mathrm{HT}$ by less than $1 \%$ is reached when adding $1 \% \mathrm{CF}$ to the $\mathrm{AM}$ insert compared to an insert without CF.

Brass leads to a significantly higher impact on HT as shown in Table 4 where influencing factors of $1 \mathrm{~kg}$ of the materials are listed. ABS has a higher impact on the LCA as compared to PE-LD with an accelerated impact due to its chemical composition and its production chain.

\begin{tabular}{l|c|c|c|c|c|c|c} 
& VP 0 \% & VP 5\% & VP 10\% & aluminum & brass & steel & carbon fibers \\
\hline GWP in $\mathrm{kgCO}_{2}$ eq & 3.118 & 3.769 & 4.419 & 18.971 & 5.045 & 1.744 & 16.127 \\
HT in kg1, 4 - DBeq & 621.790 & 596.313 & 570.835 & 269.738 & 4772.948 & 85.757 & 112.236
\end{tabular}

Table 4. LCA data for $1 \mathrm{~kg}$ of the inserts' materials.

\begin{tabular}{l|c|c|} 
& ABS & PE-LD \\
\hline GWP in $\mathrm{kgCO}_{2}$ eq & 3.995 & 1.896 \\
$\mathrm{HT}$ in $\mathrm{kg} 1,4-\mathrm{DB} e q$ & 7.057 & 2.486
\end{tabular}

Table 5. LCA data for $1 \mathrm{~kg}$ of the parts' materials.

Waste is responsible for $60 \%$ of the necessary injected polymer and makes up for up to $33 \%$ of the contributions for 1 shot as shown in Table 6 for 1 shot. The factors were calculated as ratio of impact of waste to overall impact of necessary parts and waste. ABS can be considered more influential in both factors with a high impact on the LCA.

When neglecting the contributions of the polymer waste, CFs have a strong impact on the LCA of the IM process. Even at higher shot numbers, the GWP 


\begin{tabular}{l|c|c|c|c|c|c} 
& VP 0 \% & VP 5 \% & VP 10\% & aluminum & brass & steel \\
\hline GWP ratio of ABS & 0.3301 & 0.2857 & 0.2508 & 0.0159 & 0.0194 & 0.0569 \\
HT ratio of ABS & 0.0043 & 0.0044 & 0.0046 & 0.0020 & 0.0000 & 0.0022 \\
\hline GWP ratio of PE-LD & 0.1576 & 0.1318 & 0.1128 & 0.0061 & 0.0075 & 0.0224 \\
HT ratio of PE-LD & 0.0012 & 0.0013 & 0.0013 & 0.0006 & 0.0000 & 0.0006
\end{tabular}

Table 6. Ratios of waste material as compared to the total of GWP and HT impacts for 1 shot.

contributions to the 4 inserts VP $10 \%$ in the IM machine remains significantly below the GWP of the metal materials and VP $5 \%$ competes with steel at higher shot numbers as can be seen in Fig. 3 .

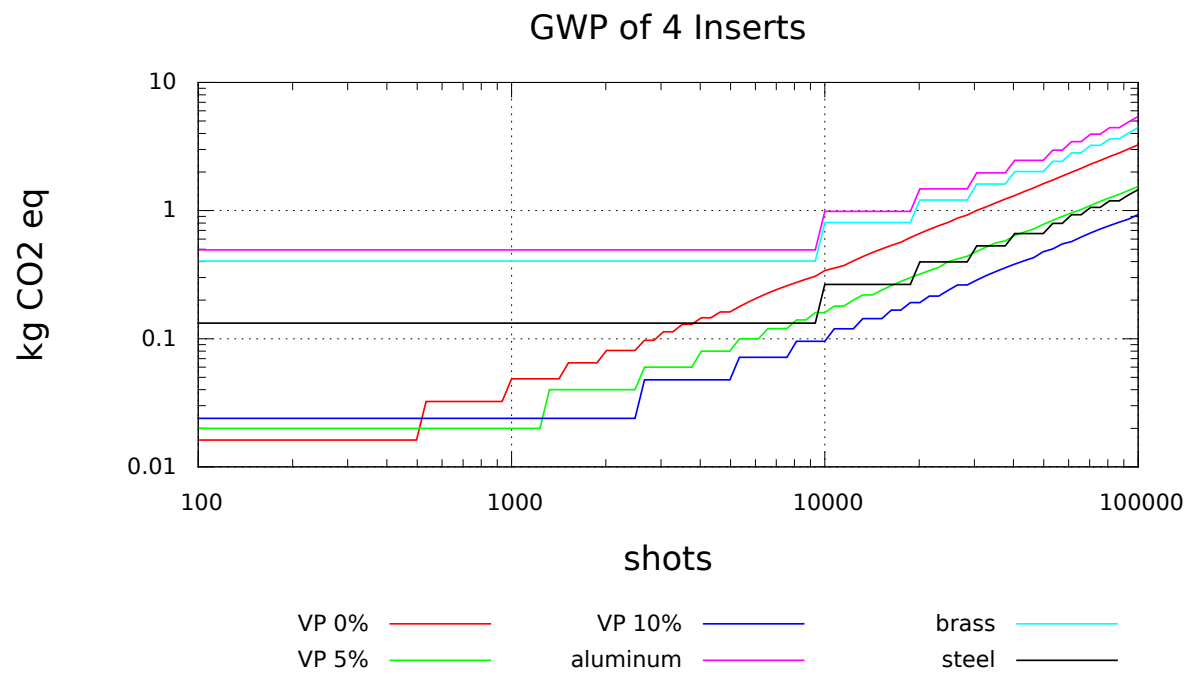

Fig. 3. Cumulative GWP impact neglecting the polymer waste.

Due to the high effects of the photopolymer on HT, the AM inserts remain between aluminum and steel below and brass exceeding the impact. Still, smaller production numbers below 5000 shots favor the AM inserts as suitable alternatives for prototyping applications as shown in Fig. 4.

It is moreover noticeable that the GWP of both ABS as well as LD-PE waste remains high compared to the inserts' materials. The contributions of the waste component of the IM process overrules the contributions of the insert material on the GWP as shown in Fig. 5 and Fig. 6. At higher shot numbers, the ratio converges to 1 meaning that the inserts' materials have negligible contribution to the global impact. 


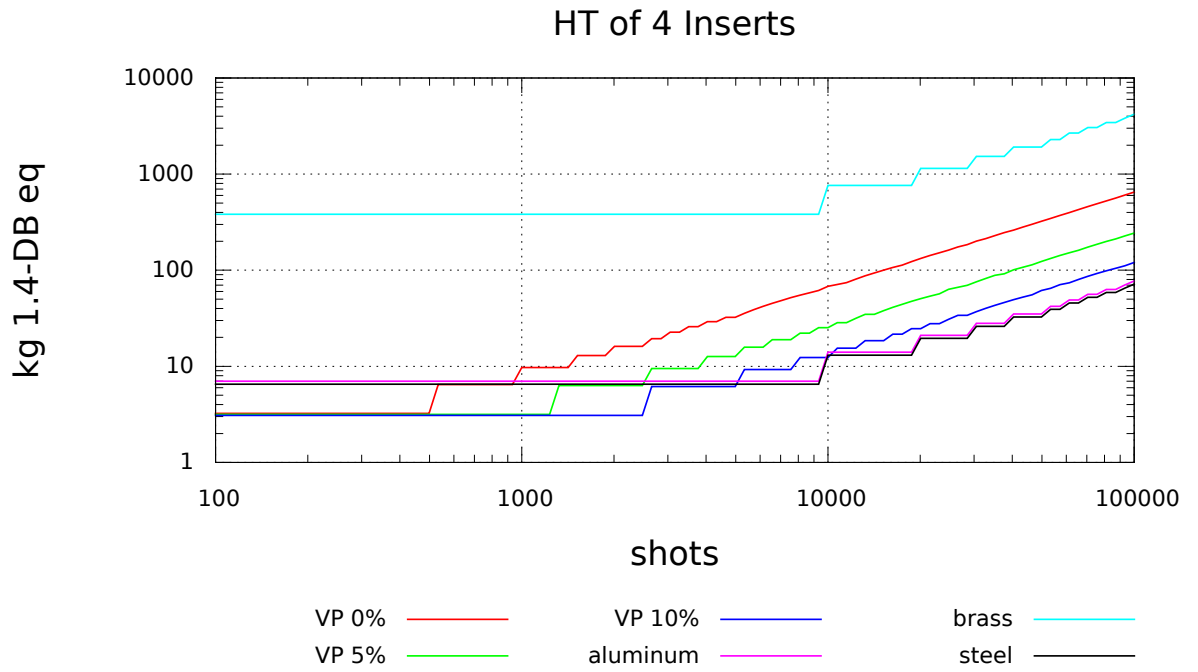

Fig. 4. Cumulative HT impact neglecting the polymer waste.

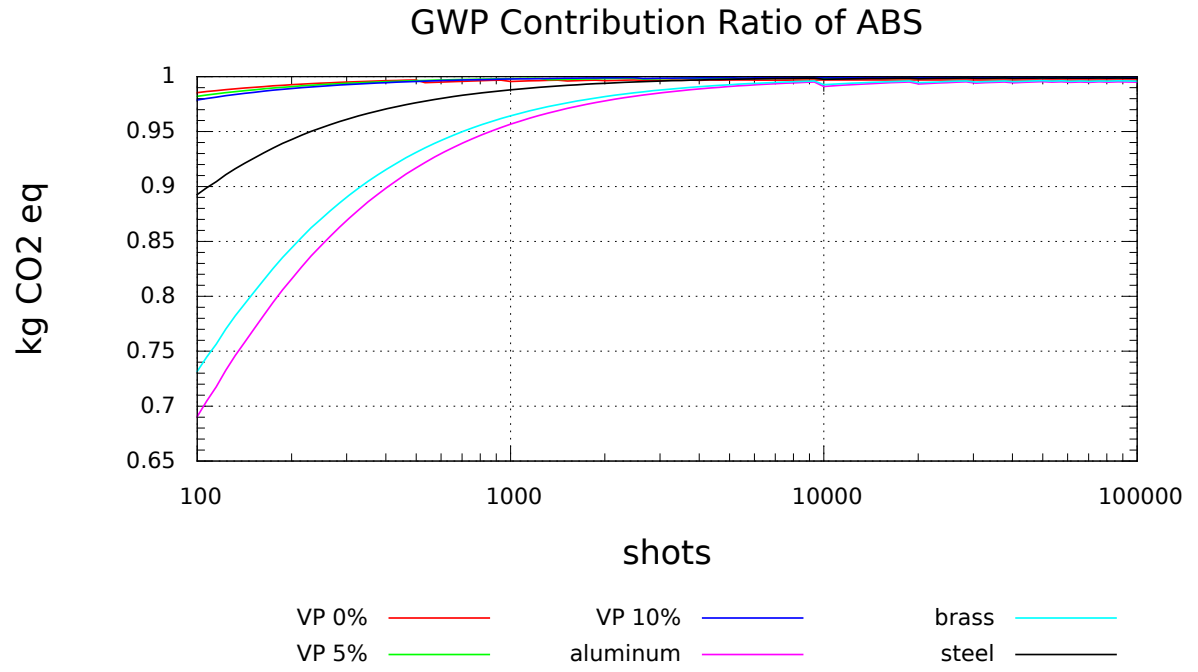

Fig. 5. Ratio of GWP impact of ABS waste material as compared to the total impact on the LCA. 
GWP Contribution Ratio of PE-LD

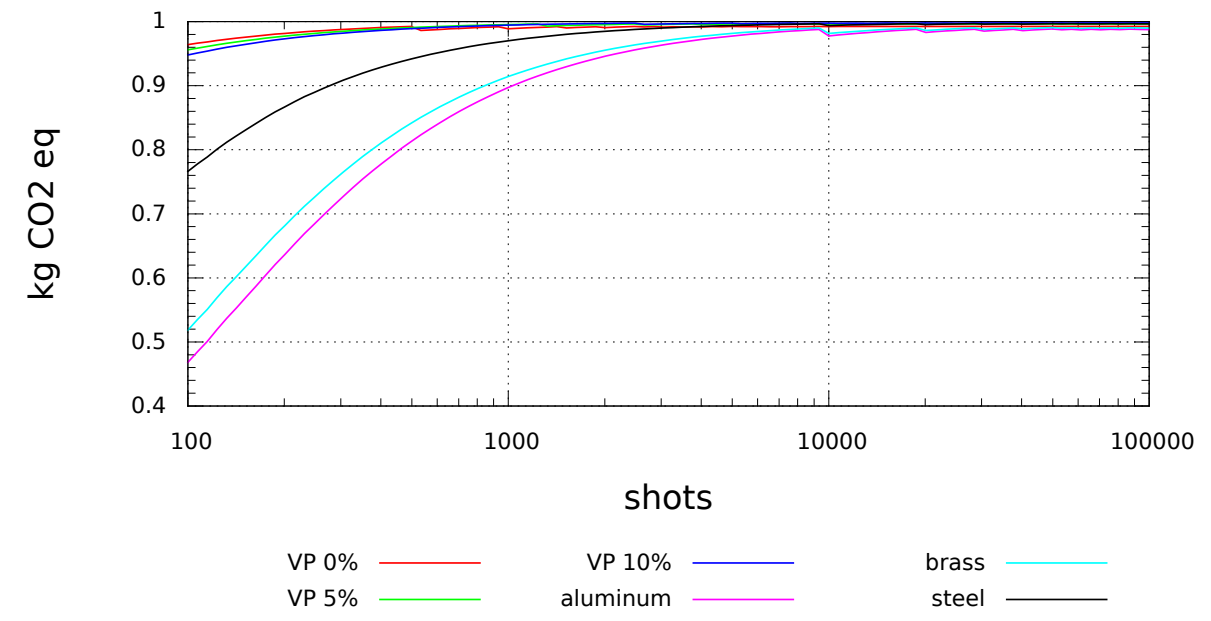

Fig. 6. Ratio of GWP impact of PE-LD waste material as compared to the total impact on the LCA.

Due to the poor performance of brass in terms of HT, the contributions of waste ABS and PE-LD remains at $20 \%$ for brass in terms of ABS waste (Fig. 7) and $10 \%$ for brass in terms of PE-LD waste (Fig. 8). Production of VP $0 \%$ inserts is influenced up to $63 \%$ in terms of ABS waste and up to $40 \%$ in terms of PE-LD waste. Better performance of FRPs in the AM inserts in terms of lifetime results in a higher contribution of the waste material.

\section{Conclusion}

As a conclusion, the IM manufacturing process needs revision in terms of produced polymer waste that does not contribute to the part or the mold. Production of ABS and PE-LD parts was not dominated by the difference in the insert material, but by the environmental impact of ABS and PE-LD parts and waste production.

CFs have a significant influence on the performance of AM inserts in the LCA. Concerning GWP contributions, AM inserts with a ratio of $10 \%$ wt have a preferable performance than metal inserts.

AM inserts are most suitable for smaller production volumes in terms of their environmental impact, manufacturing costs and time as well as feature accuracy.

Due to the lower lifetime of AM inserts in the IM process, metal inserts are preferred for series production of high part volumes whereas AM inserts are preferred in all key aspects for prototyping of low to medium volume production. 


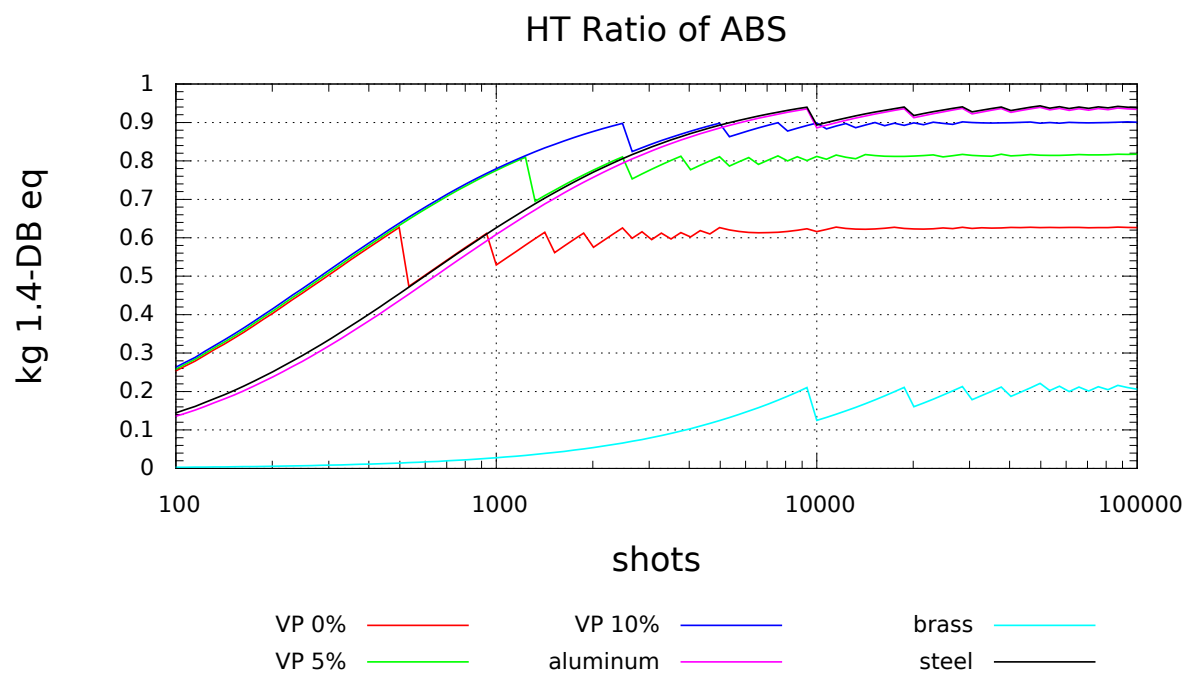

Fig. 7. Ratio of HT impact of ABS waste material as compared to the total impact on the LCA.

\section{HT Ratio of PE-LD}
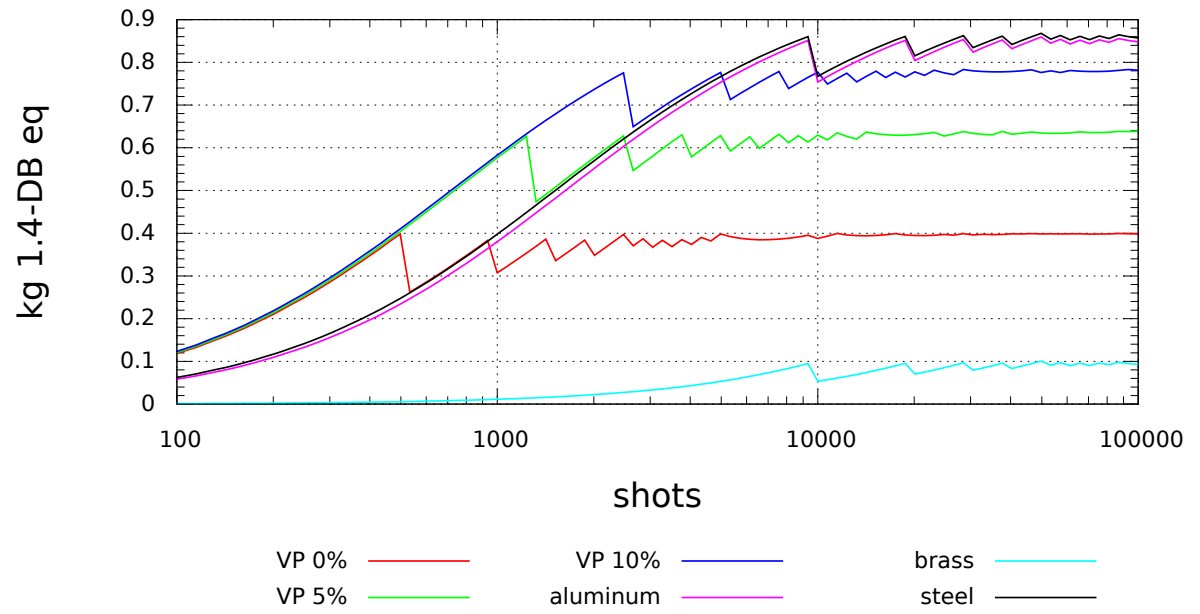

Fig. 8. Ratio of HT impact of PE-LD waste material as compared to the total impact on the LCA. 


\section{References}

1. Thomas Hofstätter, Michael Mischkot, David Bue Pedersen, Guido Tosello, and Hans Nørgaard Hansen. Evolution of surface texture and cracks during injection molding of fiber-reinforced, additively-manufactured, injection molding inserts. In Proceedings of Aspe Summer Topical Meeting 2016. ASPE-The American Society for Precision Engineering, 2016.

2. Jozsef Gabor Kovacs. Construction of pre-deformed shapes for rapid tooling in injection molding. In Macromolecular symposia, volume 239, pages 259-265. WileyBlackwell, 111 River Street Hoboken NJ 07030-5774 USA, 2006.

3. JG Kovacs, G Kortelyesi, NK Kovacs, and A Suplicz. Evaluation of measured and calculated thermal parameters of a photopolymer. International Communications in Heat and Mass Transfer, 38(7):863-867, 2011.

4. T Tábi, NK Kovács, IE Sajó, T Czigány, S Hajba, and JG Kovács. Comparison of thermal, mechanical and thermomechanical properties of poly (lactic acid) injection-molded into epoxy-based rapid prototyped (polyjet) and conventional steel mold. Journal of Thermal Analysis and Calorimetry, 123(1):349-361, 2016.

5. Sadegh Rahmati and Phill Dickens. Rapid tooling analysis of stereolithography injection mould tooling. International Journal of Machine Tools and Manufacture, 47(5):740-747, 2007.

6. Michael Mischkot, Thomas Hofstätter, Niki Bey, David Bue Pedersen, Hans Nørgaard Hansen, and Michael Z Hauschild. Life cycle assessment injection mold inserts: Additively manufactured, in brass, and in steel. In Proceedings of the DTU Sustain Conference 2015. DTU-Technocal University of Denmark, 2015.

7. Thomas Hofstätter, Niki Bey, Michael Mischkot, Andreas Lunzer, David Bue Pedersen, and Hans Nørgaard Hansen. Comparison of conventional injection mould inserts to additively manufactured inserts using life cycle assessments. In Proceedings of Euspen's 16th International Conference \& Exhibition. EUSPEN-European Society for Precision Engineering and Nanotechnology, 2016.

8. Martin Parry, Osvaldo F Canziani, Jean P Palutikof, Paul J van der Linden, Clair E Hanson, et al. Climate change 200\%: impacts, adaptation and vulnerability, volume 4. Cambridge University Press Cambridge, 2007.

9. Ralph K. Rosenbaum, Till M. Bachmann, Lois S. Gold, Mark A.J. Huijbregts, Olivier Jolliet, Ronnie Juraske, Annette Köhler, Henrik Fred Larsen, Matthew MacLeod, Manuele Margni, Thomas E. McKone, Jerme Payet, Marta Schuhmacher, Dik van de Meent, and Michael Zwicky Hauschild. Usetox - the unepsetac toxicity model: recommended characterisation factors for human toxicity and freshwater ecotoxicity in life cycle impact assessment. International Journal of Life Cycle Assessment, 13(7):532-546, 2008.

10. Michael Mischkot, Hans Nørgaard Hansen, and David Bue Pedersen. Additive manufacturing for the production of inserts for micro injection moulding. In Proceedings of Euspen's 15th International Conference $\&$ Exhibition, 2015.

11. Megan Kreiger and Joshua M Pearce. Environmental life cycle analysis of distributed three-dimensional printing and conventional manufacturing of polymer products. ACS Sustainable Chemistry \& Engineering, 1(12):1511-1519, 2013.

12. Young S Song, Jae R Youn, and Timothy G Gutowski. Life cycle energy analysis of fiber-reinforced composites. Composites Part A: Applied Science and Manufacturing, 40(8):1257-1265, 2009. 
13. FP La Mantia and M Morreale. Green composites: A brief review. Composites Part A: Applied Science and Manufacturing, 42(6):579-588, 2011.

14. Thomas Hofstätter, David Bue Pedersen, Guido Tosello, and Hans Nørgaard Hansen. Applications of fiber-reinforced polymers in additive manufacturing. In Proceedings of the 1st Cirp Conference on Composite Materials Parts Manufacturing. CIRP, 2017.

15. Thomas Hofstätter, David Bue Pedersen, Guido Tosello, and Hans Nørgaard Hansen. State-of-the-art of fiber-reinforced polymers in additive manufacturing technologies. Journal of Reinforced Plastics and Composites, 0(0):1-13, 2017.

16. International Organization for Standardization. Iso 14040/44:2006 environmental management - life cycle assessment - principles and framework. 2006.

17. Zoltek. Zoltek px35 milled carbon fibers technical data sheet. 2015.

18. Jannick Højrup Schmidt and J Watson. Eco island ferry: Comparative lca of island ferry with carbon fibre composite based and steel based structures. Technical report, 2.-0 LCA consultants, 2014.

19. Toray Industries Inc. Carbon fiber and global environment, 2017. 